Rev. Estud. Ling., Belo Horizonte, v. 30, n. 1, p. 319-350, 2022

\title{
Caminos de gramaticalización de construcciones perifrásticas: el quichua santiagueño y su relación con otras lenguas de la familia quechua
}

\section{Grammaticalization paths of pheriphrastic constructions: Santiagueño Quichua and its relations with other Quechua languages}

\author{
Mayra Juanatey \\ Consejo Nacional de Investigaciones Científicas y Técnicas (CONICET), Buenos \\ Aires / Argentina \\ mjuanatey@conicet.gov.ar \\ https://orcid.org/0000-0003-3461-840X
}

\begin{abstract}
Resumen: El quichua santiagueño (familia quechua, Sudamérica) cuenta con diferentes construcciones perifrásticas con verbos auxiliares. Muchas de estas construcciones presentan distintos tipos de variación sincrónica (fonológica, morfológica y sintáctica) que responden a la coexistencia de formas nuevas y formas antiguas, según pudo ser relevado en fuentes primarias, secundarias y en instancias de elicitación. De esta manera, entendiendo que los estudios sobre gramaticalización y la gramática diacrónica de construcciones son enfoques complementarios, este trabajo propone una hipótesis de cambio lingüístico para las construcciones perifrásticas del quichua santiagueño basada en un modelo de gramaticalización que responde al ciclo perífrasis-fusiónerosión y a la extensión de un patrón, originado en las construcciones con converbos, hacia otras construcciones similares. El reconocimiento de construcciones y caminos de gramaticalización similares en lenguas de otras ramas de la familia lingüística permite aportar a las observaciones existentes sobre el vínculo del quichua santiagueño con otras lenguas de la familia.
\end{abstract}

Palabras clave: gramaticalización; reconstrucción sintáctica; quechua; quichua santiagueño.

Abstract: Santiagueño Quichua (Quechua, South America) exhibits multiple periphrastic constructions with auxiliar verbs. Many of these constructions are 
in synchronic variation (phonological, morphological and syntactic) as there is a coexistence of new and old forms. This was observed in primary and secondary sources and during elicitation. As the grammaticalization and diachronic construction grammar are complementary approaches, this work outlines a hypothesis of linguistic change for the periphrastic constructions of Quichua Santiagueño based on a grammaticalization path that responds to the periphrasis-fusion-erosion cycle and the extension of a pattern originated in the converb construction. The recognition of this constructions and similar changes in other branches of the linguistic family allows us to contribute to the existing observations on the position of Quichua Santiagueño among other Quechua languages.

Keywords: grammaticalization; syntactic reconstruction; Quechua; Quichua Santiagueño.

Recebido em 15 de junho de 2021.

Aceito em 23 de agosto de 2021.

\section{Introducción}

El quichua santiagueño presenta diversas construcciones perifrásticas o multiverbales con verbo auxiliar. Se entiende aquí por verbos auxiliares a las formas que pertenecen a una subclase cerrada de verbos que expresan la persona, número, género, aspecto, tiempo, modo y modalidad y pueden impartir un significado aspectual a toda la construcción (AIKHENVALD, 2011, p. 14). Los verbos auxiliares en quichua santiagueño varían entre los verbos copulativos $k a-$ y tiya- o el verbo $r i$ - 'ir'. Por otra parte, las formas léxicas de estas construcciones en el quichua están señaladas mediante algunos de los sufijos nominalizadores, $-q 0-s q a$, o el converbo $-s$. En este trabajo se analizan tres construcciones perifrásticas, que se presentan a continuación.

En primer lugar, existe una construcción perifrástica para expresar aspecto progresivo. Como se ilustra en (1), esta consiste en un verbo cópula locativo auxiliar tiya- y un verbo léxico con el sufijo $-s$, llamado 'converbo' en esta investigación (siguiendo a Juanatey, 2020b). 


\begin{tabular}{|c|c|c|c|c|}
\hline \multirow{3}{*}{ (1) } & celulares-ni-oq & asi-s & rima-s & tiya-nku \\
\cline { 2 - 5 } & celulares-EUF-PROP & reír-CONV & hablar-CONV & cop.loc-3PL \\
\cline { 2 - 5 } & \multicolumn{4}{|c|}{ 'Están hablando, riéndose, con los celulares.' } \\
\hline
\end{tabular}

La lengua cuenta a su vez con un sufijo verbal de aspecto progresivo $-c h k a^{2}$. A pesar de que el marcador de progresivo como un afijo está extendido en la familia quechua, la estrategia multiverbal también se presenta en otras lenguas.

Una segunda perífrasis es aquella que expresa aspecto habitual. Las nominalizaciones con el sufijo - $q$ (NMLZ) más el verbo auxiliar copulativo $k a$ - conforman esta construcción, como se ve en (2). Esta perífrasis es común a toda la familia quechua (CERRÓN-PALOMINO, 2003).

\begin{tabular}{|c|c|c|c|c|}
\hline \multirow{2}{*}{$(2)$} & mana & $y a q a$ & rima-q & $\boldsymbol{k a - r a - n i}$ \\
\cline { 2 - 5 } & NEG & casi & hablar-NMLZ & COP-PAS-1SG \\
\cline { 2 - 5 } & \multicolumn{4}{|c|}{ '(Yo) casi no solía hablar.' } \\
\hline
\end{tabular}

lmente, se presenta aquí también una construcción multiverbal con verbo auxiliar que expresa futuro y que está conformada por una forma léxica nominalizada con el sufijo $-q$ y el verbo auxiliar $r i$ - 'ir', como se ve en (3).

\begin{tabular}{|l|c|c|c|}
\hline (3) & chay-ta & ruwa-q & ri-ni \\
\cline { 2 - 4 } & eso-AC & hacer-NMLZ & ir-1SG \\
\cline { 2 - 4 } & \multicolumn{3}{|c|}{ 'Voy a hacer eso.' } \\
\hline
\end{tabular}

Esta construcción no se encuentra en todas las lenguas de la familia. En general, en la familia quechua ejemplos como los de (3) con el nominalizador $-q$ y el verbo auxiliar $r i$ - 'ir' son codificaciones de relaciones de movimiento con propósito, es decir, relaciones en las que uno de los eventos -el de movimiento- se lleva a cabo para permitir la realización del otro (CRISTOFARO, 2013). En el quichua santiagueño, paralelamente a la construcción de movimiento con propósito que también existe en la lengua, la construcción se ha gramaticalizado como una perífrasis de futuro. Esta última coexiste con otra de futuro flexivo (ALBARRACÍN, 2011). El desarrollo de una construcción multiverbal de futuro con base en el verbo 'ir' está bien documentado tipológicamente, incluso para otras lenguas quechua, como el ecuatoriano (HEINE; KUTEVA, 2002, p.161) o el ayacuchano (ZARIQUIEY; CÓRDOVA, 2008).

${ }^{1}$ Los datos sin mención de la fuente son producto de trabajos de campo propios.

2 Esta forma tiene variación en la familia quechua como -shka, -sha, -sa, en lenguas sureñas, $0-y k a$ en lenguas del quechua I. En el quichua ecuatoriano el morfema es $-k u$. 
En este trabajo se propone un estudio de la variación sincrónica de las construcciones de perifrásticas de progresivo, habitualidad y futuro en quichua santiagueño, en vistas a extraer conclusiones respecto de su desarrollo diacrónico. De esta manera, se plantean las siguientes hipótesis: la variación sincrónica existente en las construcciones perifrásticas del quichua santiagueño es evidencia de un cambio lingüístico en proceso que responde al modelo cíclico de perífrasis-fusión-erosión (CROFT, 2003). Asimismo la construcción perifrástica de aspecto progresivo con un verbo léxico con forma de converbo constituye un patrón que se encuentra en extensión hacia las otras dos construcciones. Finalmente, este trabajo sostiene que la comparación de las construcciones con converbos en las diferentes lenguas de la familia, constituye un aporte a nuestro conocimiento de la relación entre las lenguas de la familia.

A continuación se dedica una primera sección para presentar el quichua santiagueño desde el punto de vista de su filiación con otras lenguas de la familia y sus rasgos tipológicos más relevantes. Luego se presentan los conceptos teóricos de referencia para esa investigación. En la sección siguiente se desarrollan las hipótesis de cambio lingüístico para las tres construcciones perifrásticas. Finalmente se presentan las discusiones en torno a la comprobación de las hipótesis y, por último, las conclusiones.

\section{El quichua santiagueño y la familia lingüística quechua}

La familia lingüística quechua se extiende en un área discontinua a lo largo de la Cordillera de los Andes desde el departamento de Caquetá, Nariño y Putumayo en el sur de Colombia hasta la Provincia de Santiago del Estero en el noroeste de Argentina (ADELAAR; MUYSKEN, 2004). El siguiente mapa muestra su extensión geográfica a través de Colombia, Ecuador, Perú, Bolivia, norte de Chile y Argentina. 
Figura 1 - Mapa de la familia lingüística quechua

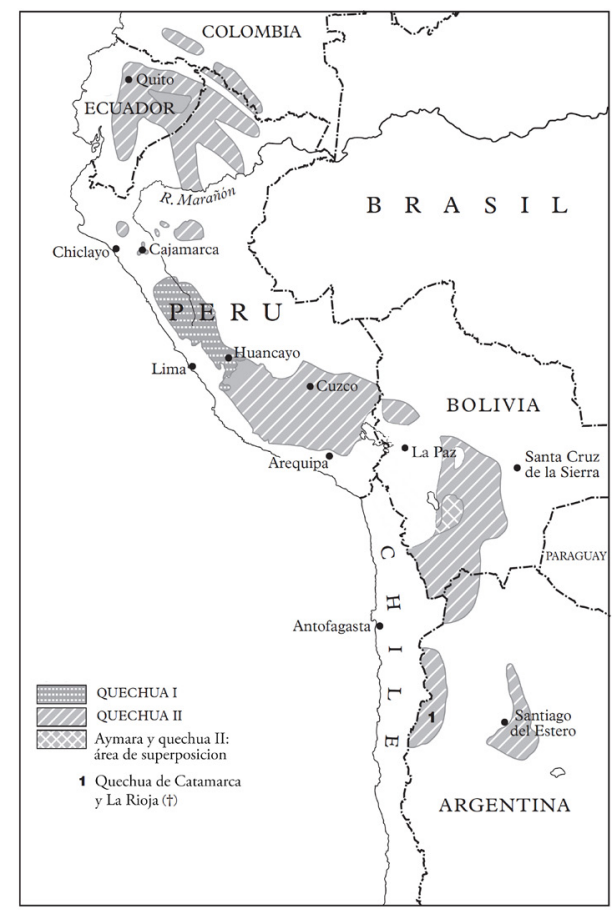

Fuente: Adelaar y Muysken (2004, p. 169).

El quichua santiagueño se ubica en la subrama QIIC que comprende las lenguas habladas hacia el sur de la extensión total de la familia, aproximadamente, desde los departamentos de Junín y Huancavélica en Perú, se expande por el sur de Perú, Bolivia hasta el norte chileno y argentino. El sector central de esta extensión ha sido denominado grupo cusqueño-boliviano, quedando en la periferia principalmente el quechua de Ayacucho y el de Santiago del Estero (ADELAAR, 1994; CERRÓN-PALOMINO 2003; ADELAAR; MUYSKEN, 2004; entre otros). En el siguiente esquema se presenta la ubicación de esta rama y del quichua santiagueño, en relación con las demás lenguas de la familia. 
Figura 2 - Quichua santiagueño en la familia quechua

\begin{tabular}{|c|c|c|c|c|c|c|c|}
\hline \multicolumn{8}{|c|}{ FAMILIA QUECHUA } \\
\hline \multicolumn{4}{|c|}{ QI HUAHUASH } & \multicolumn{4}{|c|}{ QII HUAMPUY } \\
\hline & CENTRAL & & PACARAOS & & & & \\
\hline \multirow[t]{2}{*}{ HUAILAY } & AP-AM-AH & HUANCAY & & \multicolumn{2}{|c|}{ QIIA YUNGAY } & \multicolumn{2}{|c|}{ QIIB-C CHINCHAY } \\
\hline & & & & CENTRAL & SEPTENTRIONAL & QIIB SEPTENTRIONAL & QIIC MERIDIONAL \\
\hline Huailas & Alto-Pativilica & Yaru & & Laraos & Cañaris- & Amazonas & Ayacucho \\
\hline \multirow[t]{4}{*}{ Conchucos } & Alto Marañón & Jauja Huanca & & Lincha & Incahuasi & San Martín & Cusco \\
\hline & Alto Huallaga & Huangascar- & & Apuri & Cajamarca & Loreto & Bolivia \\
\hline & & Topará & & Chocos & & Colombia & Santiagueño \\
\hline & & & & Modeán & & Ecuador & \\
\hline
\end{tabular}

Basado en: Cerrón-Palomino (2003).

A pesar de sus diferenciaciones internas, la familia quechua comparte, en general, ciertos rasgos tipológicos que la caracterizan en su fonología, morfología y sintaxis. Respecto de la fonología, el quichua santiagueño al igual que otras lenguas de la familia presenta un sistema de tres vocales /a, i, u/ con los alomorfos /e, o/ en contextos de oclusivas postvelares y una acentuación grave (salvo excepciones que se dan en quichua santiagueño como producto de la deleción de algunas sílabas finales). Por otra parte, la morfología es aglutinante y sufijante. Se trata de una lengua de alineamiento transitivo nominativo-acusativo, de marcación en el núcleo (personas sujeto y persona objeto de primera y segunda) y marcación en el dependiente, mediante un sistema de casos. En el verbo pueden indicarse categorías de TAME y en los dependientes, además de caso, también puede marcarse evidencialidad, número y posesión. El orden de constituyentes del santiagueño tiende a ser SVO y modificado-modificador (a diferencia de otras lenguas quechua). Las relaciones interclausales se establecen principalmente mediante la nominalización de la cláusula dependiente y un sistema de conmutación de la referencia (switch-reference) de dos miembros, exclusivo para relaciones adverbiales.

Los trabajos histórico-comparativos disponibles para la familia quechua (PARKER, 2014; TORERO, 2002; CERRÓNPALOMINO, 2003, fundamentalmente) han omitido como datos para sus reconstrucciones el estudio de las construcciones perifrásticas, como las que son objeto de este estudio. Esto se debe, según mi entender, a dos razones centrales. En primer lugar, estos estudios se han centrado en 
aspectos de la fonología, el léxico y, en menor medida, la morfología. A diferencia de esto, esta investigación se alinea con los estudios que sostienen que las construcciones sintácticas son también susceptibles de ser comparadas entre lenguas hijas y reconstruidas (BARĐDAL; EYTHÓRSSON, 2012; BARĐDAL et al., 2015). De esta manera, la comparación sintáctica también permitiría echar luz sobre las hipótesis de filiación genética y clarificaría los aspectos de la prehistoria de las lenguas (LEHMANN, 1995). En segundo lugar, las lenguas quechuas se caracterizan por una abundancia de sufijos verbales para indicar significados aspectuales, direccionales y modales. A diferencia de otras lenguas de la familia, como por ejemplo otras lenguas quechua sureñas, muchos matices aspectuales tienen su contraparte perifrástica o no tienen expresión mediante sufijos en el quichua santiagueño. Esto significa que muchos significados que son expresados en otras lenguas de la familia mediante sufijos, en el quichua santiagueño probablemente sean expresados mediante una perífrasis y esos sufijos, o ya no sean productivos, o no sean empleados. ${ }^{3}$

Para el desarrollo posterior se trabajó con datos propios de campo, realizado durante el periodo 2013-2020 con hablantes en la provincia de Santiago del Estero y Buenos Aires, Argentina. Como producto de los datos de campo y de fuentes secundarias (trabajos de descripción gramatical, antologías de textos recopilados y literarios, música, etc.), se conformó un corpus del quichua santiagueño, integrado por narraciones de experiencia personal y sobre temas tradicionales, conversaciones espontáneas, textos instruccionales, música, entrevistas y elicitación de oraciones. La recolección de los datos se realizó tomando en cuenta los lineamientos de la lingüística de campo (MUNRO, 2001) y la lingüística de la documentación (GIPPERT; HIMMELMANN; MOSEL, 2006). Durante el año 2020 y 2021 se realizaron algunas elicitaciones en modalidad virtual, a causa del confinamiento preventivo como respuesta a la situación sanitaria.

\section{Gramaticalización y gramática diacrónica de construcciones}

Los estudios sobre la gramaticalización se proponen reponer el proceso direccional y cíclico por el cual un ítem léxico o gramatical desarrolla funciones gramaticales o más gramaticales en un cierto

3 Se entiende aquí por perífrasis tanto a la construcción formada por un verbo léxico más un verbo auxiliar, como también al término más general, es decir, la expresión de un significado mediante dos o más elementos. 
contexto sintagmático (pueden consultarse varias definiciones, como Lehmann, 1985; Heine y Reh, 1984, entre otros). Croft (2000, p. 159$64)^{4}$ ofrece una explicación al ciclo de gramaticalización mediante un modelo de cambio lingüístico que consiste en tres fases: perífrasisfusión-erosión. La primera remite a la emergencia de una nueva construcción perifrástica, es decir, de más de un elemento o un elemento novedoso, para una función existente, ya sea a causa de la creatividad del hablante, porque se trata de una función antes no existente en la lengua o por una motivación pragmática. Durante la segunda, la expresión perifrástica anterior pasa a interpretarse mentalmente como una unidad fija (afectada por procesos de gramaticalización como la rigidificación, obligatorificación, paradigmatización, en términos de Lehmann, 1985), es decir, se convencionaliza socialmente y, por lo tanto, reduce su variación. Finalmente, en la última fase del ciclo de gramaticalización, la expresión convencionalizada se erosiona, generalmente, fonológicamente. Subyace aquí el principio de economía que prevé que los elementos muy frecuentes e invariables tienden a reducirse. Si sigue avanzando esta última fase de erosión, el elemento puede volverse ininterpretable y el ciclo de perífrasis-fusión-erosión puede volver a comenzar.

Los estudios de gramaticalización son complementarios con las perspectivas construccionales del cambio lingüístico. ${ }^{5}$ En palabras de Traugott:

La gramática de construcciones abarca mucho de lo discutido en la literatura sobre gramaticalización mientras que también va más allá para incluir cambios morfosintácticos de mayor alcance que los que se han considerado en la mayoría de los trabajos sobre gramaticalización hasta la fecha. Esto se debe a que la arquitectura de la gramática de la construcción exige pensar tanto en términos de significado como de forma y no solo de construcciones sustantivas individuales sino también de esquemas abstractos. (TRAUGOTT, 2015, p. 52; la traducción es propia)

En estos términos, el hecho de observar los procesos de gramaticalización desde una perspectiva construccional permite apreciar que los cambios pueden llevar a la creación de nuevas construcciones y a

\footnotetext{
${ }^{4}$ Siguiendo a Keller (1990/1994) quien a su vez sigue a Lüdtke $(1980 ; 1985 ; 1986)$.

5 Una construcción desde este enfoque se piensa en términos de emparejamiento de forma y contenido. Por lo tanto, las construcciones cuentan con propiedades fonológicas, morfológicas y sintácticas que se corresponden simbólica y convecionalmente con propiedades semánticas, pragmáticas y discursivas (CROFTC 2001, p. 18).
} 
la reconfiguración de las existentes, lo que nos permite ser más precisos acerca del reconocimiento de dónde ocurren los cambios y cuál es su naturaleza (GISBORNE; PATTEN, 2011).

Una perspectiva construccional apoya firmemente la idea de que la coincidencia de patrones es un factor importante en el cambio, porque se destaca la existencia de conjuntos (sets) y la pertenencia de los elementos lingüísticos a conjuntos. Así, en términos generales, se prevé la existencia de un elemento almacenado en la memoria, generalmente una construcción, con el que se compara otro con propiedades parcialmente similares. Si suficientes personas hacen comparaciones similares con suficiente frecuencia, se puede percibir un patrón que luego se convierte en un modelo con el que se puede hacer coincidir otro elemento (TRAUGOTT, 2015, p. 64).

De esta manera, los ítems con alta frecuencia son concomitantes con las características de los ítems de más productividad, en los términos dados por Barðal (2008). Esto es que están más disponibles como modelos para extensiones -desarrollan nuevas funciones, ocurren con otros ítems, están disponibles para atraer ítems existentes, etc.--; exhiben un alto grado de generalidad -son esquemáticamente abiertos, cuentan con una amplia cobertura, etc.--; y son más regulares -se combinan más fácilmente, son operativos, están basados en reglas, son transparentes, etc.--

La frecuencia de tipo (type frequency; BYBEE, 1985, p. 132-33), es decir, el número total de tipos que pueden instanciar una construcción, y la coherencia semántica, es decir, la consistencia encontrada entre todos los miembros de cada construcción, predicen el grado de productividad de la construcción. En las construcciones sintácticas, la productividad puede estimarse en qué tan extensible es esa construcción a nuevos tipos. La extensión de patrones regulares a tipos lingüísticos existentes también fue denominada en la literatura como "regularización", "generalización", "nivelación analógica" o "productividad".

Finalmente, esta investigación se alinea con los estudios de reconstrucción sintáctica, herederos de trabajos como Harris y Campbell (1995), que han logrado avanzar recientemente en el conocimiento de la sintaxis histórica en varias familias lingüísticas. Según estos trabajos, la comparación de construcciones sintácticas puede aportar al estudio de la filiación genética de las lenguas, ya que las mismas pueden ser consideradas cognados, siendo, por lo tanto susceptibles de ser comparadas entre lenguas hijas y reconstruidas, como lo son los fonemas o lexemas. 


\section{Hipótesis de gramaticalización de construcciones perifrásticas}

A continuación se presentan las hipótesis de caminos de gramaticalización de tres construcciones perifrásticas de la lengua. A partir de la variación existente en la sincronía se trazan los posibles estadíos de cambio de cada construcción.

\subsection{Perífrasis de progresivo}

La primera construcción que será considerada es la que expresa aspecto progresivo o durativo. La lengua cuenta con un sufijo verbal de valor aspectual para indicar aspecto progresivo y, paralelamente, existe una construcción perifrástica que consiste en un verbo cópula locativo auxiliar y un verbo léxico con el converbo $-s$. Véanse los ejemplos (4) y (5).

\begin{tabular}{|c|c|}
\hline \multirow{2}{*}{$(4)$} & rima-chka-nku \\
\cline { 2 - 3 } & hablar-PROG-3PL \\
\cline { 2 - 2 } & 'Están hablando.' \\
\hline
\end{tabular}

\begin{tabular}{|c|c|c|c|c|}
\hline \multirow{2}{*}{ (5) } & celulares-ni-oq & asi-s & rima-s & tiya-nku \\
\cline { 2 - 5 } & celulares-EUF-PROP & reír-CONV & hablar-CONV & COP.LOC-3PL \\
\cline { 2 - 5 } & \multicolumn{3}{|c|}{ 'Están hablando, riéndose, con los celulares.' } \\
\hline
\end{tabular}

Se trata de una construcción que se encuentra presente en otras lenguas de la familia, en el español, que es lengua de contacto con la mayoría de las lenguas de la familia quechua, incluido el quichua santiagueño, y es, asimismo, un camino tipológicamente atestiguado de formación de progresivo. Según Bybee, Perkins y Pagliuca (1994), la gramaticalización de los progresivos suele tener como ámbito sintáctico la construcción de verbo principal + converbo o gerundio, evolucionando hacia otra en la que el verbo principal pasa a ser un auxiliar y el converbo se reinterpreta como verbo léxico.

Por lo tanto, en una instancia temprana de gramaticalización, esta construcción cuenta con un converbo, es decir, una forma verbal no finita cuya función principal es la marcación de la subordinación adverbial. Según Haspelmath (1995) los converbos se tratan de 'adverbios verbales'. Tipológicamente los converbos son más frecuentes en relaciones temporales, de manera o causales (NEDJALKOV, 1995), es decir, relaciones típicamente expresadas por formas sintácticamente reducidas.

En el quichua santiagueño, el converbo es altamente frecuente en construcciones que se extienden a lo largo de un continuum de integración entre eventos (Juanatey (2020b) siguiendo el paralelismo 
entre el dominio de la expresión sintáctica y la dimensión funcional propuesto por Lehmann (1988); Van Valin (2005) para las relaciones interclausales). Hacia el polo de menor integración el converbo puede expresar relaciones entre eventos de secuencialidad, causa, circunstancia, mientras que se especializa y es más frecuente en relaciones más estrechas de modificación adverbial, para expresar medio, posición/movimiento y manera. A continuación se ilustra una relación de circunstancia (integrada) y otra de manera (+ integrada).

\begin{tabular}{|c|c|c|c|}
\hline \multirow{3}{*}{$(6)$} & huella- $p$ & $a m u-s$ & $q a a-r a-\varnothing$ \\
\cline { 2 - 4 } & huella-LOC & venir-CONV & ver-PAS-3SG \\
\cline { 2 - 4 } & \multicolumn{3}{|c|}{ 'Mientras venía por la huella lo vio.' } \\
\hline
\end{tabular}

\begin{tabular}{|c|c|c|}
\hline \multirow{3}{*}{ (7) } & muyu-s & ura-ko-ra- $\varnothing$ \\
\cline { 2 - 3 } & girar-CONV & bajar-RFL-PAS-3SG \\
\cline { 2 - 3 } & \multicolumn{2}{|c|}{ 'Bajó girando/rodando.' } \\
\hline
\end{tabular}

En una siguiente etapa de gramaticalización hacia la construcción de progresivo, la relación entre el converbo y el verbo finito se ve afectada por procesos de: fosilización y desemantización del verbo principal (para pasar a interpretarse como auxiliar), fijación de la posición converboverbo auxiliar y aumento de la esquematicidad de la construcción que pasa a expresar un significado aspectual. Respecto del verbo auxiliar, nótese que la desemantización del verbo finito en la lengua aún no es total, sino que se conserva una opción entre una construcción con eventos sin movimiento, donde se emplea un auxiliar tiya- 'estar (COP.LOC)', como en (8), y otra para acciones de más movimiento, donde es más frecuente como verbo principal puri- 'andar', como en (9).

\begin{tabular}{|c|c|c|c|}
\hline \multirow{3}{*}{$8)$} & $q a a-s$ & tiya- $n k u$ & hora-t \\
\cline { 2 - 4 } & ver-CONV & COP.LOC-3PL & hora-AC \\
\cline { 2 - 4 } & \multicolumn{3}{|c|}{ 'Están mirando la hora.' } \\
\hline
\end{tabular}

\begin{tabular}{|c|c|c|c|}
\hline \multirow{2}{*}{$9)$} & muyu-s & puri-sa & ka-ra- $\varnothing$ \\
\cline { 2 - 4 } & girar-CONV & andar-NML.ANT & COP-PAS-3SG \\
\hline
\end{tabular}

Por lo anterior, se desprende que será posible una desemantización y fijación léxica del verbo auxiliar en un etapa de gramaticalización posterior. En este caso, el verbo auxiliar tiya- se fija para todo tipo de verbos léxicos, como puede verse en (10). 


\begin{tabular}{|c|c|c|}
\hline \multirow{3}{*}{$(10)$} & chaya-s & tiya-n \\
\cline { 2 - 3 } & llegar-CONV & COP.LOC-3SG \\
\cline { 2 - 3 } & \multicolumn{2}{|c|}{ 'Está llegando.' } \\
\hline
\end{tabular}

La gramaticalización de una construcción multiverbal con verbo auxiliar más verbo léxico terminado en -s o -sh, también se presenta en otras lenguas de la familia. Por ejemplo, en el quechua de Chachapoyas (QIIB), como puede verse en (11) (HINTZ, 2017, p. 323).

\begin{tabular}{|l|c|c|}
\hline \multirow{3}{*}{$(11)$} & \multicolumn{2}{|c|}{ Quechua Chachapoyas } \\
\cline { 2 - 3 } & shamu-sh & tiya- $n$ \\
\cline { 2 - 3 } & venir-MS ${ }^{6}$ & COP.LOC-3SG \\
\cline { 2 - 3 } & \multicolumn{2}{|c|}{ '(Ella/él) está viniendo.' } \\
\hline
\end{tabular}

Según Hintz (2017), la coaelescencia de la terminación -sh con el comienzo de la cópula, del ejemplo anterior, se gramaticaliza posteriormente como marcador de progresivo: -shtiya, ilustrado en (12) (HINTZ, 2017, p. 323). Formas similares, como -shti, -sti o -stin también identificadas en otras lenguas, como el quechua ayacuchano (CERRÓN-PALOMINO, 2003), tarmeño (ADELAAR, 1977), cusqueño (CUSIHUAMAN, 1976), entre otros, se han gramaticalizado en marcadores de simultaneidad.

\begin{tabular}{|c|c|}
\hline (12) & Quechua Chachapoyas \\
\cline { 2 - 3 } & shamu-shtiya- $n$ \\
\cline { 2 - 3 } & venir-PROG-3SG \\
\cline { 2 - 3 } & '(Ella/él) está viniendo.' \\
\hline
\end{tabular}

En la siguiente figura se resumen los estadíos de gramaticalización de esta construcción. Se incluye como última etapa la fusión, aunque esta aún no fue advertida para el quichua santiagueño:

6 Se conserva la glosa de Hintz ms 'mismo sujeto', ya que desconozco si se trata de una forma paralela al sufijo $-s$ en quichua santiagueño. 
Figura 3 - Proceso de gramaticalización de construcción perifrástica de aspecto progresivo

\section{Construcción 1}

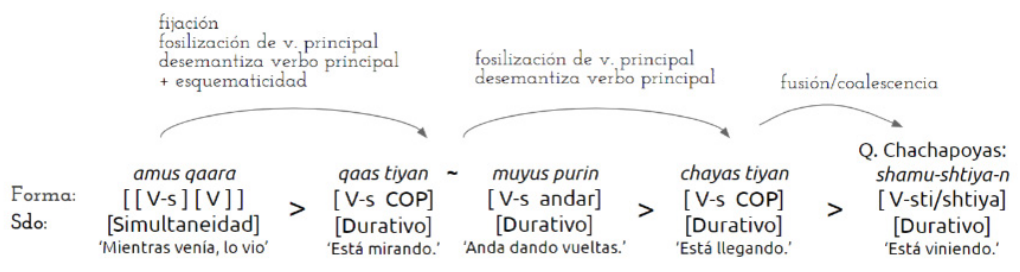

Paralelamente al desarrollo de la construcción de progresivo a partir de la relación entre un verbo principal y un converbo, se observó en quichua santiagueño la posibilidad de la expresión de una perífrasis para expresar aspecto incoativo con verbos léxicos meteorológicos y con un predicado principal de movimiento parcialmente desemantizado amu- 'venir'. Como se ve en (13).

\begin{tabular}{|c|c|c|}
\hline \multirow{2}{*}{ (13) } & para-s & amu-n \\
\cline { 2 - 3 } & llover-CONV & venir-3SG \\
\cline { 2 - 3 } & \multicolumn{2}{|c|}{ 'Empezó a llover.' } \\
\hline
\end{tabular}

La semántica del predicado de movimiento se vuelve más esquemática y pasa a referir a un desplazamiento espacio-temporal del fenómeno meteorológico hacia el hablante. Trabajos tipológicos, como Heine y Kuteva (2002, p. 309), mencionan la posibilidad de que un venitivo se vuelva marcador de incoativo en una lengua (masái, Nilo-Sahariana). En otras lenguas quechua, como el cusqueño, el sufijo direccional cisclocativo -mu también puede aportar lecturas aspectuales incoativas con verbos atmosféricos y verbos que indican emergencia desde dentro del cuerpo humano, un objeto, la tierra o un cuerpo de agua. Subyace la idea de que algo que sucede en otro lugar se incorpora al campo de percepción del hablante de manera gradual o continua (KERKE; MUYSKEN, 2011, p.160). Véase el ejemplo (14) (KALT, 2015, p. 36).

\begin{tabular}{|c|c|}
\hline (14) & Quechua cusqueño \\
\cline { 2 - 3 } & para-mu-chka-n \\
\cline { 2 - 3 } & 1lover-CIS-PROG-3SG \\
\cline { 2 - 2 } & 'Está lloviendo.' (hablante/oyente es afectado) \\
\hline
\end{tabular}


En el quichua santiagueño el sufijo - $m u$ ya no es productivo, en tanto, no puede extenderse su uso a otros ítems, sino que se encuentra fijado a algunas bases verbales, como pusa- 'llevar (animados)', pusa:mu'traer (animados)'. Por lo que podría considerarse que luego de una fase de fijación del sufijo direccional y pérdida de productivadad, el quichua santiagueño da inicio nuevamente a una fase de perífrasis para expresar estos significados mediante una relación entre una forma converbal y un auxiliar venitivo.

\subsection{Perífrasis de habitualidad}

La segunda construcción perifrástica que se tendrá en cuenta en este trabajo expresa aspecto habitual. Esta construcción está conformada mediante un verbo léxico nominalizado y una cópula como verbo auxiliar. Se reitera a continuación el ejemplo (2) como (15).

\begin{tabular}{|c|c|c|c|c|}
\hline \multirow{3}{*}{$(15)$} & mana & $y a q a$ & rima-q & ka-ra-ni \\
\cline { 2 - 5 } & NEG & \multicolumn{4}{|c|}{ casi } & hablar-NMLZ & COP-PAS-1SG \\
\cline { 2 - 5 } & \multicolumn{4}{|c|}{ '(Yo) casi no solía hablar.' } \\
\hline
\end{tabular}

Las nominalizaciones constituyen la principal estrategia de la lengua para la introducción de cláusulas dependientes. Las cláusulas nominalizadas con el sufijo - $q$ están orientadas a la expresión del agente del verbo base y, a la vez, expresan un evento en desarrollo, es decir, que su interpretación en términos temporo-aspectuales depende de la marcación morfológcia del verbo principal (JUANATEY, 2020b, p. 164182). Las nominalizaciones con $-q$ se especializan en la introducción de cláusulas relativas, como puede verse en los ejemplos siguientes.

\begin{tabular}{|l|c|c|c|c|c|}
\hline \multirow{3}{*}{$(16)$} & $q o-q o-r a-n i$ & $s u k$ & qari & {$[k a r u-p i$} & $k a w s a-q-t a]_{\mathrm{CREL}}$ \\
\cline { 2 - 6 } & dar-dar-PAS-1SG & un & hombre & lejos-LOC & vivir-NMLZ-AC \\
\cline { 2 - 6 } & \multicolumn{5}{|c|}{ 'Se lo di a un hombre que vivía lejos.' } \\
\hline \multirow{2}{*}{$(17)$} & {$[$ escuela-pi } & llamka-q $]_{\mathrm{CREL}}$ & huella- $p$ & $a m u-n$ \\
\cline { 2 - 6 } & escuela-LOC & trabajar-NMLZ & huella-LOC & venir-3SG \\
\hline
\end{tabular}

Por lo tanto, la construcción perifrástica para expresar habitualidad es producto de la fijación de las posiciones verbo dependiente-principal y la fosilización de la cópula $k a$ - como verbo finito auxiliar. Esta construcción resultante es común a toda la familia quechua (CERRÓNPALOMINO, 2003). 
Los estudios sobre gramaticalización, como Bybee, Perkings y Pagliuca (1994) y Heine y Kuteva (2002), señalan con respecto a este tipo de construcciones que el verbo "vivir" o "existir" es fuente de gramaticalización de marcadores de habitualidad. Esta tendencia tipológica puede comprobarse para las lenguas de la familia quechua, que suelen emplear la cópula ka- para expresar existencia. En el quichua santiagueño, los predicados existenciales suelen expresarse con el verbo copula locativo tiya- aunque también es posible, de manera menos frecuente, hacerlo con el verbo cópula ka-, como en (18).

\begin{tabular}{|c|c|c|}
\hline \multirow{3}{*}{$(18)$} & arenales & $k a-n k u$ \\
\cline { 2 - 3 } & arenales & COP-3PL \\
\cline { 2 - 3 } & \multicolumn{2}{|c|}{ 'Hay arenales.' } \\
\hline
\end{tabular}

Por lo tanto, podría considerarse que la construcción perifrástica de expresión de habitualidad se haya gramaticalizado a partir de una relación interclausal entre una cláusula relativa nominalizada y la cópula $k a-$, en tanto este sea considerado en su significado para el evento "existir". Esto podría haber sucedido en un estadío anterior de la lengua, en el que la expresión de la "existencia" haya sido más habitual con esta cópula, como lo es en el resto de la familia quechua.

La siguiente etapa en el proceso de gramaticalización de esta construcción se corresponde con una etapa de alternancia, en la que se encuentran en variación dos formas, como puede verse en el siguiente par.

\begin{tabular}{|l|ll|l|}
\hline \multirow{2}{*}{$(19)$} & llamkaq kan & \multicolumn{1}{c|}{ llamkas kan } \\
\cline { 2 - 3 } & \multicolumn{3}{|c|}{ 'Suele trabajar.' } \\
\hline
\end{tabular}

Así, en esta construcción es frecuente que se modifique la articulación de la oclusiva postvelar del nominalizador $-q[\mathrm{q}]$ por [s] para señalar el mismo significado (como ya fue advertido por Albarracín, 2011, p. 44). Asimismo para la tercera persona y, en caso de continuidad referencial, puede elidirse la cópula auxiliar que lleva la marcación de tiempo y persona (ALBARRACÍN, 2011, p. 43), pero solo cuando el verbo léxico lleva $-q$ y no cuando es con $-s$.

Finalmente, se postula aquí una última etapa de gramaticalización en la que el proceso inicia una fase de fusión de los dos elementos que conforman la construcción perifrástica. El inicio de esta fase puede observarse en instancias de escritura de hablantes en distintos medios, fundamentalmente, en redes sociales. Siendo que la escritura del quichua santiagueño no se encuentra aún completamente estandarizada y, si lo estuviera, no existen instancias de democratización de la escritura de lengua para la población en general (como lo sería por ejemplo la 
educación intercultural bilingüe), los/as hablantes realizan sus propias hipótesis de escritura. Por lo tanto, es habitual encontrar instancias como (20), pero son aún más frecuentes en la escritura la fusión de la construcción con el verbo léxico finalizado en $-s$, como en (21).

\begin{tabular}{|c|c|c|c|}
\hline \multirow{3}{*}{ (20) } & una & jinetia-j:ka-ra-ni & che-ina \\
\cline { 2 - 4 } & unay & jinetia-q:ka-ra-ni & cha-ina \\
\cline { 2 - 4 } & hace.tiempo & jinetear-NMLZ:COP-PAS-1SG & DEM.MED-COMP \\
\cline { 2 - 4 } & \multicolumn{3}{|c|}{ 'Hace tiempo solía jineatear así.' } \\
\hline
\end{tabular}

\begin{tabular}{|c|c|c|c|}
\hline \multirow{4}{*}{$(21)$} & chay & ca-s:ca-ra & caballitu-y \\
\cline { 2 - 4 } & chay & ka-s:ka-ra- $\varnothing$ & caballitu-y \\
\cline { 2 - 4 } & DEM.MED & COP-S:COP-PAS & caballito-POS.1SG \\
\cline { 2 - 4 } & $y$ & esuela-man & pusa-a-s:ca-ra \\
\cline { 2 - 4 } & $y$ & escuela-man & pusa- $\boldsymbol{a}$-s:ka-ra- $\varnothing$ \\
\cline { 2 - 4 } & $y$ & escuela-DIR & llevar.anim-OBJ.1SG-S:COP-PAS-3SG \\
\cline { 2 - 4 } & \multicolumn{3}{|c|}{ 'Ese solía ser mi caballo y solía llevarme a la escuela.' } \\
\hline
\end{tabular}

A continuación en la Figura 2 se resume el camino de gramaticalización para las construcciones de aspecto habitual desarrollado anteriormente.

Figura 4 - Proceso de gramaticalización de construcción perifrástica de aspecto habitual

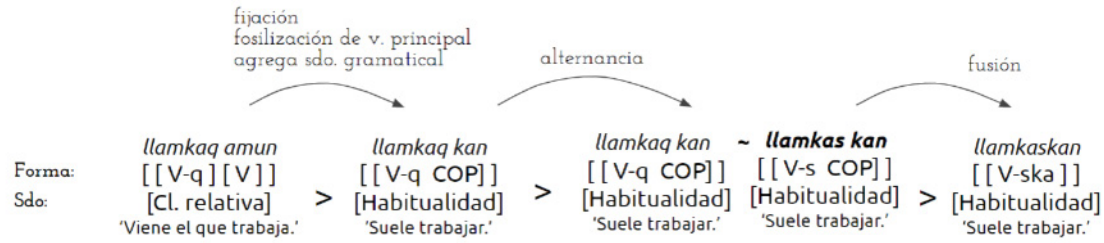

\subsection{Perífrasis de futuro}

La última construcción que será considerada en este trabajo es una perífrasis que expresa tiempo futuro y que está conformada por una

7 Se conserva para estos ejemplos en una primera línea la ortografía original de los mensajes en las redes sociales y en la segunda la ortografía estandarizada empleada en este artículo. 
forma léxica nominalizada con el sufijo $-q$ y el verbo auxiliar $r i$ - 'ir', como se ve en (22), repetido de (3).

\begin{tabular}{|c|c|c|c|}
\hline \multirow{2}{*}{$(22)$} & chay-ta & ruwa-q & $\boldsymbol{r i - n i}$ \\
\cline { 2 - 4 } & DEM.DEM-AC & hacer-NMLZ & ir-1SG \\
\cline { 2 - 3 } & \multicolumn{3}{|c|}{ 'Voy a hacer eso/haré eso.' } \\
\hline
\end{tabular}

Esta construcción coexiste en la lengua con un paradigma de futuro flexivo, como puede verse en (23). Sin embargo, aún no se han desarrollado estudios que describan las particularidades de uno u otro uso. Por lo pronto, es preciso notar que la construcción multiverbal es la más frecuente en el habla espontánea. ${ }^{8}$

\begin{tabular}{|c|c|}
\hline (23) & ruwa-saq \\
\cline { 2 - 3 } & hacer-FUT.1SG \\
\cline { 2 - 3 } & (Haré.) \\
\hline
\end{tabular}

En general, en la familia quechua, ejemplos como los de (22) con el nominalizador $-q$ y el verbo auxiliar $r i$ - 'ir' son codificaciones de relaciones de movimiento con propósito, es decir, relaciones en las que uno de los eventos -el de movimiento- se lleva a cabo para permitir la realización del otro (CRISTOFARO, 2005). Así, en otras lenguas quechua no pueden emplearse para expresar una acción que no implique desplazamiento. Véase el siguiente ejemplo del quechua de Junín (CERRÓN-PALOMINO, 1976; en DE GRANDA, 1997, p. 4)

\begin{tabular}{|c|c|c|c|}
\hline \multirow{3}{*}{$(24)$} & \multicolumn{3}{|c|}{ Quechua Junín } \\
\cline { 2 - 4 } & [caarru & alli-q] & yalquqlu- $n$ \\
\cline { 2 - 4 } & automóvil & buscar-NMLZ & salir-3SG \\
\cline { 2 - 4 } & \multicolumn{3}{|c|}{ 'Salió a buscar un automóvil.' } \\
\hline
\end{tabular}

El desarrollo de una construcción multiverbal de futuro con base en el verbo 'ir' está bien documentado tipológicamente, incluso para otras lenguas quechua, como el ecuatoriano (HEINE; KUTEVA, 2002), ilustrado en (25), o el ayacuchano (ZARIQUIEY; CÓRDOVA, 2008).

8 Según Albarracín (2011, p. 35) la distribución de ambas formas no es exactamente la misma. La autora no incluye una explicación a esta variación. 


\begin{tabular}{|c|c|c|}
\hline \multirow{3}{*}{$(25)$} & \multicolumn{2}{|c|}{ Quichua ecuatoriano } \\
\cline { 2 - 3 } & punu- $k$ & $r i-n i$ \\
\cline { 2 - 3 } & dormir-NMLZ & ir-1SG \\
\cline { 2 - 3 } & 'Voy a dormir/dormiré.' (MARCHESE, 1986 en HEINE; KUTEVA, 2002, p. 162.) \\
\hline
\end{tabular}

Además de esta evidencia tipológica que puede ejemplificarse también dentro de la familia quechua, pueden consultarse Albarracín (2011, p. 36) y Juanatey (2020a; 2020b), para diferentes desestimaciones de la hipótesis de de Granda (1997, p. 35), quien propone que se trata de un reanálisis de la estructura quechua que expresaba movimiento, producto de la transferencia lingüística por contacto con el español. Sobre la expresión del movimiento con propósito, se ha identificado en Juanatey (2020a) que la lengua ha desarrollado otra estrategia perifrástica paralela: un converbo que expresa el evento de movimiento (señalado mediante el sufijo $-s$ ) seguido de un evento de propósito que se realiza como un verbo finito.

Luego de esta primera etapa de gramaticalización a partir de una construcción de movimiento con propósito, donde el verbo auxiliar $r i$ - 'ir' se ha fosilizado como verbo auxiliar y desemantizado, y toda la construcción agrega el significado temporal de futuro, puede identificarse una siguiente etapa de alternancia de la posición verbo léxico-verbo auxiliar, como se ve en (26).

\begin{tabular}{|l|l|l|}
\hline \multirow{2}{*}{$(26)$} & llamkaq rin & rin llamkaq \\
\cline { 2 - 3 } & \multicolumn{2}{|c|}{ 'Voy a trabajar/trabajaré.' } \\
\hline
\end{tabular}

En una fase posterior, esta alternancia parece fijarse en la posición verbo léxico-verbo auxiliar, dando lugar a una nueva variación, esta vez relativa a la terminación del verbo léxico, en [q] o en [s], es decir, la misma variación observada para las construcciones de aspecto habitual descriptas en la sección anterior. Ejemplos de este tipo no se encuentran en fuentes secundarias, ya que la relación entre una forma verbal terminada en $-s$ y un verbo finito, se interpreta generalmente como una relación de modificación adverbial, similar al ejemplo (27). Por lo tanto, en la escritura la perífrasis de futuro siempre suele normalizarse en la terminación $-q$.

Modificación adverbial: converbo $(-s)+$ verbo finito (ri-) 


\begin{tabular}{|c|c|c|}
\hline \multirow{3}{*}{$(27)$} & wayrakacha-s & re-ra-ø \\
\cline { 2 - 3 } & correr-CONV & ir-PAS-3SG \\
\cline { 2 - 3 } & \multicolumn{2}{|c|}{ 'Iba corriendo.' (en tanto, se desplazaba corriendo) } \\
\hline
\end{tabular}

Sin embargo, es posible reconstruir esta etapa de alternancia gracias a que se encuentran una gran cantidad de ejemplos de escritura en redes sociales o en textos no normalizados, en los que se observa la hipótesis de escritura realizada por los hablantes. Estos ejemplos corresponden a un estadío posterior a la alternancia verbo léxico terminado en [q] o [s] y verbo auxiliar, ya que se presentan como la fusión de la terminación $-s$ con el verbo auxiliar, como los siguientes.

(28) Futuro (fusión $-s+r i$-)

\begin{tabular}{|c|c|c|c|c|}
\hline \multirow[t]{5}{*}{ a. } & cha & hombre & chaya-spa & noqayku \\
\hline & DEM.MED & hombre & llegar-CONT & 1PL.EXCL \\
\hline & \multicolumn{2}{|c|}{ mula-n-ta-q } & \multicolumn{2}{|c|}{ larga-po-ø-s:ri-ykus } \\
\hline & \multicolumn{2}{|c|}{ mula-POS.ESG-AC-Q } & \multicolumn{2}{|c|}{ largar-APL-BEN.3SG-s:ir-1PL.EXCL-IMP } \\
\hline & \multicolumn{4}{|c|}{$\begin{array}{l}\text { 'Cuando llegue ese hombre nosotros a la mula le vamos a soltar.' } \\
\text { (GUILLÍN et al. 2012, p. 69) }\end{array}$} \\
\hline \multirow[t]{3}{*}{ b. } & \multicolumn{2}{|c|}{ badera.bajada } & \multicolumn{2}{|c|}{ tiya-s:ri-ni } \\
\hline & \multicolumn{2}{|c|}{ Bandera.Bajada } & \multicolumn{2}{|c|}{ COP.LOC-S:ir-1SG } \\
\hline & \multicolumn{4}{|c|}{ 'Voy a estar en Bandera Bajada.' } \\
\hline \multirow[t]{3}{*}{ c. } & noca & ca-s:ri-ni & \multicolumn{2}{|c|}{ bandoneonista } \\
\hline & noqa & $k a-s: r i-n i$ & \multicolumn{2}{|c|}{ bandoneonista } \\
\hline & $1 \mathrm{SG}$ & COP-S:ir-1SG & \multicolumn{2}{|c|}{ bandoneonista } \\
\hline
\end{tabular}

Esta fusión fue advertida ya en otras lenguas de la familia, como en el quichua ecuatoriano que desarrolló a partir de esta construcción (-k ri-) el sufijo -gri, como en (29) (MUYSKEN, 1977, en CERRÓNPALOMINO, 2003, p. 283).

\begin{tabular}{|c|c|}
\hline \multirow{3}{*}{ (29) } & Quichua ecuatoriano \\
\cline { 2 - 3 } & puñu-gri-ni \\
\cline { 2 - 3 } & dormir-FUT-1SG \\
\cline { 2 - 3 } & 'voy a dormir' . \\
\hline
\end{tabular}

En el quichua ecuatoriano de las tierras bajas, de la región de Napo y Pastaza, se ha desarrollado este sufijo como producto de la fusión, pero según Nuckolls (1990), conserva su matiz semántico de 
desplazamiento espacial, expresando una acción que debe llevarse a cabo en un futuro en otra locación.

En la siguiente figura se resumen los estadíos del proceso de gramaticalización de la construcción de perífrasis de futuro. En la primera línea se indican las observaciones sobre el santiagueño y en paralelo se agregaron los datos similares del ecuatoriano.

Figura 5 - Proceso de gramaticalización de construcción perifrástica de tiempo futuro

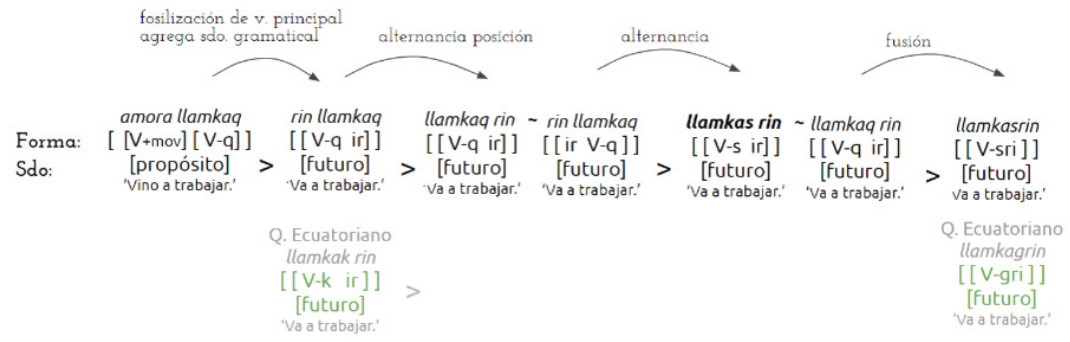

\section{Discusión}

A continuación se integra el desarrollo anterior para postular discusiones organizadas en tres ejes. El primero consiste en sistematizar las hipótesis de caminos de gramaticalización anteriores en las fases del ciclo perífrasis-fusión-erosión (CROFT, 2000). El segundo aporta una observación respecto de la extensión de un patrón originado a partir de la perífrasis de progresivo a las otras construcciones. Finalmente, se espera que este desarrollo sea un aporte a la revisión de la relación entre las lenguas de familia quechua.

\subsection{Las construcciones en el ciclo perífrasis-fusión-erosión}

Luego del desarrollo presentado anteriormente, es posible concluir que las tres construcciones analizadas emergen, en primer lugar, como una construcción perifrástica para expresar el significado progresivo o durativo, en el primer caso, el significado de aspecto habitual, en el segundo, y la expresión de tiempo futuro, en el tercero. Estas construcciones, afectadas por un proceso de gramaticalización pasan, en los tres casos, paulatinamente hacia una etapa de fusión en la que se observa una coalescencia entre la 
terminación del verbo léxico ( $-s$, en todos los casos) con el inicio del verbo auxiliar (tiya-, $k a-$ y ri-, respectivamente).

Como fue señalado, tanto la construcción perifrástica para expresar progresivo como la que expresa futuro coexisten con formas flexivas para expresar los mismos significados. Para la reconstrucción diacrónica de estos sufijos verbales también se ha postulado un origen en una forma perifrástica previa. De esta manera, para muchos de los sufijos de estructura fonológica CCV, Cerrón Palomino (2003), retomando a Stark (1985) y Muysken (1977), afirma que estos tienen un origen bimorfemático.

Así, el sufijo verbal de progresivo -shka/-chka, común las lenguas del QIIC, se reconstruye como la unión de un sufijo *-sh/*-ch final más el inicio de una cópula $k a$-. Una vez conformado este nuevo sufijo -shka/chka, algunas lenguas, como el quichua santiagueño inician una nueva fase del ciclo y una nueva perífrasis de progresivo emerge, con la misma terminación $-s /-s h$ pero esta vez con la cópula locativa tiya-. Cabe señalar al respecto que en algunas lenguas de la familia (como las otras lenguas de la rama QIIC) tiya- no se interpreta como una cópula, sino que se trata de un verbo de posición 'estar sentado'. Por lo tanto, el desarrollo de tiya- como cópula en algunas lenguas de la familia, como el quichua santiagueño o algunas lenguas norteñas, como el ecuatoriano, podría haber llevado a surgimiento de esta nueva construcción perifrástica.

Respecto de las formas para el futuro, las marcas de futuro flexivo de las lenguas quechua son propuestas como la combinación de dos morfemas. Por ejemplo, la expresión de la tercera persona futuro -nqa se trata, según Cerrón Palomino (2003), de la fusión entre un sufijo de tercera $-n$ y una protomarca de futuro *-qa. A partir de este estadío, otras lenguas como el quichua santiagueño reinician el ciclo con una nueva instancia perifrástica que a la vez, según vimos, también después se fusionará.

Para la construcción perifrástica de habitualidad, no se registra en la literatura de reconstrucción diacrónica de la familia ninguna hipótesis acerca de su protoforma. Por lo tanto, solamente tenemos conocimientos del ciclo en su fase de perífrasis y posterior fusión de la terminación - $S$ y la cópula $k a$-, descripta en la sección anterior.

Las observaciones anteriores se representan en la siguiente figura. 
Figura 6 - Ciclo de perífrasis-fusión-erosión en construcciones analizadas

\section{Conclusiones: Perífrasis > Fusión > Erosión}

\begin{tabular}{|c|c|c|c|c|c|c|c|}
\hline C1 & $\begin{array}{c}{ }^{*} \text {-ch ka- } \\
\text { [V-ch COP] } \\
\text { [Durativo] }\end{array}$ & $>$ & $\begin{array}{c}\text { qaachkan } \\
\text { [V-PROG] } \\
\text { [Durativo] } \\
\text { 'Está mirando.' }\end{array}$ & $>[\ldots]$ & $\begin{array}{c}\text { qaas tiyan } \\
\text { [V-s COP] } \\
\text { [Durativo] } \\
\text { 'Está mirando.' }\end{array}$ & $>$ & $\begin{array}{l}\text { Q. Cachapoyas: } \\
\text { shamu-shtiya-n } \\
\text { [V-shtiya/-sti] } \\
\text { [Durativo] } \\
\text { 'Está viniendo.' }\end{array}$ \\
\hline C2 & & & & {$[\ldots]$} & $\begin{array}{c}\text { llamkas kan } \\
\text { [[ V-s COP] ] } \\
\text { [Habitualidad] } \\
\text { 'Suele trabajar.' }\end{array}$ & $>$ & $\begin{array}{l}\text { Ulamkaskan } \\
\text { [[V-ska]] } \\
\text { [Habitualidad]] } \\
\text { 'Suele trabajar.' }\end{array}$ \\
\hline C3 & $\begin{array}{c}{ }^{*}-n-q a \\
{\left[\left[35 G \mathrm{~T}^{0}\right]\right]} \\
{[\text { futuro] }}\end{array}$ & $>$ & $\begin{array}{l}\text { Ulamkanga } \\
\text { [[ V-FUT] ] } \\
\text { [futuro] } \\
\text { 'Trabajará.'. }\end{array}$ & $>[\ldots]$ & $\begin{array}{c}\text { llamkas rin } \\
{[[\text { V-s ir }]]} \\
\text { [futuro] } \\
\text { 'Va a trabajar.' }\end{array}$ & $>$ & $\begin{array}{c}\text { Ulamkasrin } \\
\text { [[ V-sri ]] } \\
\text { [futuro] } \\
\text { 'Va a trabajar.' }\end{array}$ \\
\hline
\end{tabular}

\subsection{La extensión de un patrón regular}

Como ya fue señalado, el converbo es una forma muy frecuente en la lengua y está involucrada en distintas construcciones que cubren una amplia gama de significados (JUANATEY, 2020b). De esta manara, puede, por un lado, establecer relaciones entre eventos de tipo secuenciales, de causa o de simultaneidad en relación con un predicado principal. Asimismo, se observó que puede ser complemento de verbos de fase del tipo 'empezar a...' o 'terminar de...'. Sin embargo, se especializa fundamentalmente en establecer relaciones estrechas con otros predicados, como son la modificación adverbial para expresar medio, posición/movimiento y manera. Otros converbos, se han gramaticalizado para pasar a ser marcadores aspectuales de iteración (con el converbo de 'llevar') y continuidad ('ir') o ser marcadores comitativos ('tener') o de actitud proposicional ('decir'). Y, finalmente, el converbo participa de construcciones perifrásitcas. En este trabajo nos centramos en la de aspecto progresivo, pero probablemente participe de algunas otras aún no descriptas. ${ }^{9}$ Por lo tanto, los converbos son formas altamente productivas en la lengua, en los términos dados por Barðdal (2008), en tanto desarrollan nuevas funciones, cubren una amplia gama de significados y se combinan fácilmente con otros elementos para conformar nuevas construcciones.

\footnotetext{
9 He advertido la perífrasis ya descripta para verbos metoerológicos para expresar incoatividad paras amun 'viene lloviendo', una posible construcción de perfecto llamkas amun 'viene trabajando (desde hace un tiempo)' y otras combinaciones para expresar, por ejemplo, duratividad como lloqas rin 'iba subiendo', entre otras.
} 
Para los fenómenos analizados en este trabajo, se considera que una vez gramaticalizada la construcción de progresivo con el verbo léxico finalizado en la marca converbal $-s$ y fijada la posición verbo léxico-verbo auxiliar, esta actúa como un patrón de perífrasis para las otras construcciones existentes: la de habitualidad y la de tiempo futuro.

Es interesante notar, especialmente, que la alternancia [-q]/ [-s] se da en estas construcciones solamente una vez que la posición verbo léxico-verbo auxiliar se ha fijado, es decir, la posición típica del converbo en la perífrasis de progresivo. Nótese, además, que la alternancia no responde a una mera cuestión fonológica ya que, a pesar de que la relajación y adelantamiento de una articulación velar que lleva progresivamente a una sibilante $([\mathrm{q}]>[\mathrm{k}]>[\mathrm{s}])$ es un cambio fonológico muy frecuente en las lenguas del mundo, esta variación no está registrada para el quichua santiagueño en ningún otro contexto. De hecho, el santiagueño se inscribe en el QIIC junto con las otras lenguas que han conservado la distinción [q] y [k] (a diferencia de las ramas norteñas que han adelantado $[\mathrm{q}]>[\mathrm{k}]$ o incluso sonorizado en $[\mathrm{g}])$. Este cambio $>[\mathrm{s}]$ solamente puede registrarse en la posición final de estos verbos léxicos antes de los verbos auxiliares. Por lo tanto, si se tratara de un cambio fonológico, el mismo podría estar motivado por el patrón de la construcción perifrástica con converbo de progresivo.

\subsection{La reconstrucción sintáctica como evidencia de la filiación entre lenguas quechua}

La variación sincrónica, según lo desarrollado anteriormente, encuentra su lugar si se adopta una perspectiva diacrónica (CROFT, 2000), es decir que lo que se aprecia como variación sincrónica se trata de un cambio gramatical en proceso y es el insumo para extraer conclusiones acerca de la reconstrucción interna de las lenguas. Sumado a los estudios diacrónicos existentes, centrados en la fonología y morfología, se plantea aquí que la reconstrucción en el plano sintáctico permitirá echar luz sobre la relación entre las lenguas de la familia y de la región. Esto es particularmente necesario para el quichua santiagueño, dada su particular ubicación geográfica e historia. A continuación se repasan algunas observaciones que permitirían relacionar los fenómenos antes desarrollados del quichua santiagueño con otras lenguas de la familia.

En general, las lenguas quechua comparten marcadores similares para sus sistemas de conmutación de la referencia (switch-reference): - pti (y variantes como - qti) para discontinuidad y -spa (y variantes como -shpa) para señalar continuidad de la referencia (CERRÓN-PALOMINO, 
2003). Dentro de la familia quechua existen más variaciones para indicar relaciones entre eventos con mismo sujeto. Así, en las lenguas de la rama QI, el marcador más habitual para relaciones de correferencia es $-r(\mathrm{o}-l)$, aunque, por ejemplo, el quechua huallaga dentro de esta misma rama, cuenta con dos formas -shpa y $-r$ (ADELAAR; MUYSKEN, 2004, p. 189 y 225$)$.

La relación entre el par de sufijos que expresan relaciones entre eventos con continuidad de referencia, como -spa/-shpa y $-s /-r /-l$, parece ser compleja en la mayoría de las lenguas quechua y se manifiesta de forma diversa a lo largo de la familia. Para el quichua santiagueño (Bravo, 1965; Nardi, 2002; Alderetes, 2001; Albarracín , 2016 o, incluso en los trabajos comparativos sobre la familia quechua, como Cerrón-Palomino, 2003) siempre se ha señalado que el sufijo $-s$ se trata de una forma apocopada del sufijo -spa. Si bien ambas formas pueden participar de algunas relaciones adverbiales, fundamentalmente, causa y circunstancia, las construcciones converbales son más reducidas sintáctica y semánticamente que las cláusulas dependientes con marcadores de conmutación de la referencia, como fue señalado anteriormente.

Formas reducidas similares al converbo $-s$, por lo tanto, no se encuentran presentes en todas las lenguas de la familia. En lenguas de la rama QI, se advierte la forma reducida $-r$, por ejemplo en el quechua Huallaga (WEBER, 1989) y el anchashino (COLE, 1983). En las lenguas quechua de la rama QII (como se ve en el Mapa 2), es posible encontrarlo en Santiago del Estero, en la lengua en desuso de La Rioja y Catamarca -según he podido observar, probablemente con las mismas funciones aún no estudiadas- y Cerrón Palomino (2003) indica la presencia de formas en $-s /-s h$ también en Pacaraos, Chachapoyas, Azuay, Oriente de Ecuador y Colombia, es decir, todas lenguas de las ramas norteñas (QIIA y QIIB). Por el contrario, las lenguas cercanas al quichua santiagueño, es decir, las otras lenguas sureñas de la rama QIIC, como el jujeño, el boliviano, el cusqueño o el ayacuchano, no cuentan con este sufijo (a excepción, claramente, del quichua de La Rioja y Catamarca), sino que solamente cuentan con la forma correferencial similar a -spa.

Además de encontrarse este morfema en determinadas lenguas de la familia, se encuentra subdescripto. De esta manera, fue omitido de muchas gramáticas descriptivas porque siempre se lo consideró una mera variación alomórfica del sufijo -spa. Entre las descripciones disponibles, para las lenguas del QI, por ejemplo, Weber (1989) señala que -shpa y $-r$ en el quechua huallaga se emplean en contextos paralelos, aunque en ciertas oraciones suele optarse por el primero, ya que en esa lengua es el que permite la aglutinación de sufijos personales. Para el quechua 
de Ancash, Cole (1983) señala que la elección de -shpa o - $r$ depende de si las dos cláusulas son vistas como eventos relacionados, donde la ocurrencia de un evento depende del otro, o no relacionados. Algunas gramáticas de las lenguas norteñas mencionadas hacen referencia a esta forma. Respecto de las lenguas de esta región de la rama QII, por ejemplo, Taylor (2006) para el quechua de Chachapoyas indica que existe un sufijo de gerundio -sh al que ocasionalmente puede agregarse - $p a$ para formar -shpa. Sin embargo, como se ilustró en (12), es la forma erosionada -sh la que podría integrar una perífrasis de progresivo y, además, se encuentra en una fase fusión: samush tiyan > shamushtiyan. Adelaar (1986) indica para el quechua de Pacaraos que la forma -sh, podría tratarse de una erosión de -shpa ${ }^{10}$ citando el siguiente ejemplo: kantaykásh shukaykásh purinkiman 'Puedes andar cantando y silbando.' Llama la atención que el único ejemplo citado para esta forma es, precisamente, uno de modificación de manera, es decir, una relación estrecha entre eventos, que según fue advertido es expresada especialmente por el converbo $-s$ en quichua santiagueño.

Asimismo, por encontrarse subdescripto, este sufijo tampoco fue seleccionado en la literatura sobre las reconstrucciones del protoquechua. Además, es de notar que estos estudios no consideran en todos los casos estas lenguas más periféricas, como el santiagueño o las lenguas norteñas. Por ejemplo, Parker (1963) consideró algunas variedades peruanas (serranas y centrales), ecuatorianas y bolivianas, mientras que Torero (1964) amplió su estudio hacia la zona centro-norte peruana. Posteriormente, el trabajo de Cerrón Palomino (2003) logró una reconstrucción más ajustada del protoquechua a la vez que, por primera vez, detalló los procesos de cambio lingüístico. Sin embargo, su reconstrucción incluye solo marginalmente el colombiano, el boliviano y las lenguas quechua de Argentina, ya que tales variedades, según el autor, se explican a partir de otros dialectos representativos.

Sumado a lo anterior, Adelaar (1994) detecta rasgos de la fonología, léxico y morfología del quichua santiagueño que en una primera etapa estarían en relación con lenguas quechua de Bolivia del sur (QIIC) y luego, propone una segunda etapa de relexificación dónde

${ }_{10}$ También señala la existencia de otra forma -sh para las perífrasis de experiencia en el pasado del tipo "alguna vez en el pasado" seguida por un auxiliar cópula $k a-$, como en qishyāsh kay '(alguna vez) me he enfermado.' (ADELAARA 1986, p. 35). Sin embargo este sufijo parecería ser la erosión de otro sufijo -shqa empleado generalmente en lenguas quechua como nominalización de pasado. En algunos contextos la forma $-s$ del quichua santiagueño también parecería ser producto de la erosión de -sqa, fundamentalmente para formación de adjetivos $\mathrm{y}$, probablemente, depictivos. 
ingresarían otros sonidos y morfemas distintos provenientes del quechua Norteño (QIIB y QIIA):

Por sus características fonológicas, en particular la situación de las sibilantes, el quechua de Santiago del Estero se relaciona con el Grupo Quechua IIB y con los dialectos IIA de la franja norandina del Perú (Cajamarca y Ferrañafe). Algunos elementos léxicos también apuntan hacia un origen norteño (Quechua IIB o Cajamarca). [...] Desde el punto de vista de la morfología verbal y del léxico en general, el quichua de Santiago del Estero muestras semejanzas sumamente específicas con el Quechua IIC, en particular, con el dialecto Bolivia sur. (ADELAAR, 1994, s.p.)

En el siguiente mapa se señalan con un círculo las observaciones realizadas por Adelaar respecto de la relación del quichua santiagueño con otras lenguas de la familia. Por otro lado, se indican también las lenguas de la familia que cuentan con construcciones con formas terminadas en $-S$, que parecen actuar de manera similar al converbo en quichua santiagueño, pero que se encuentran actualmente subdescriptas. Respecto de los caminos de gramaticalización de las construcciones perifrásticas, pudo observarse en este trabajo en particular, que otras lenguas norteñas de la rama QIIB, como el quechua Chachapoyas o el quichua ecuatoriano, siguen caminos de cambios lingüísticos similares para las construcciones de progresivo y futuro, respectivamente. Por lo tanto, podemos ver que, según se desprende del mapa, el estudio de estas construcciones podría arrojar luz sobre la relación entre las lenguas norteñas y el quichua santiagueño, en línea con la propuesta de Adelaar. 
Figura 7 - Distribución de las lenguas quechua con morfema -s y relaciones entre lenguas identificadas por Adelaar (1994)

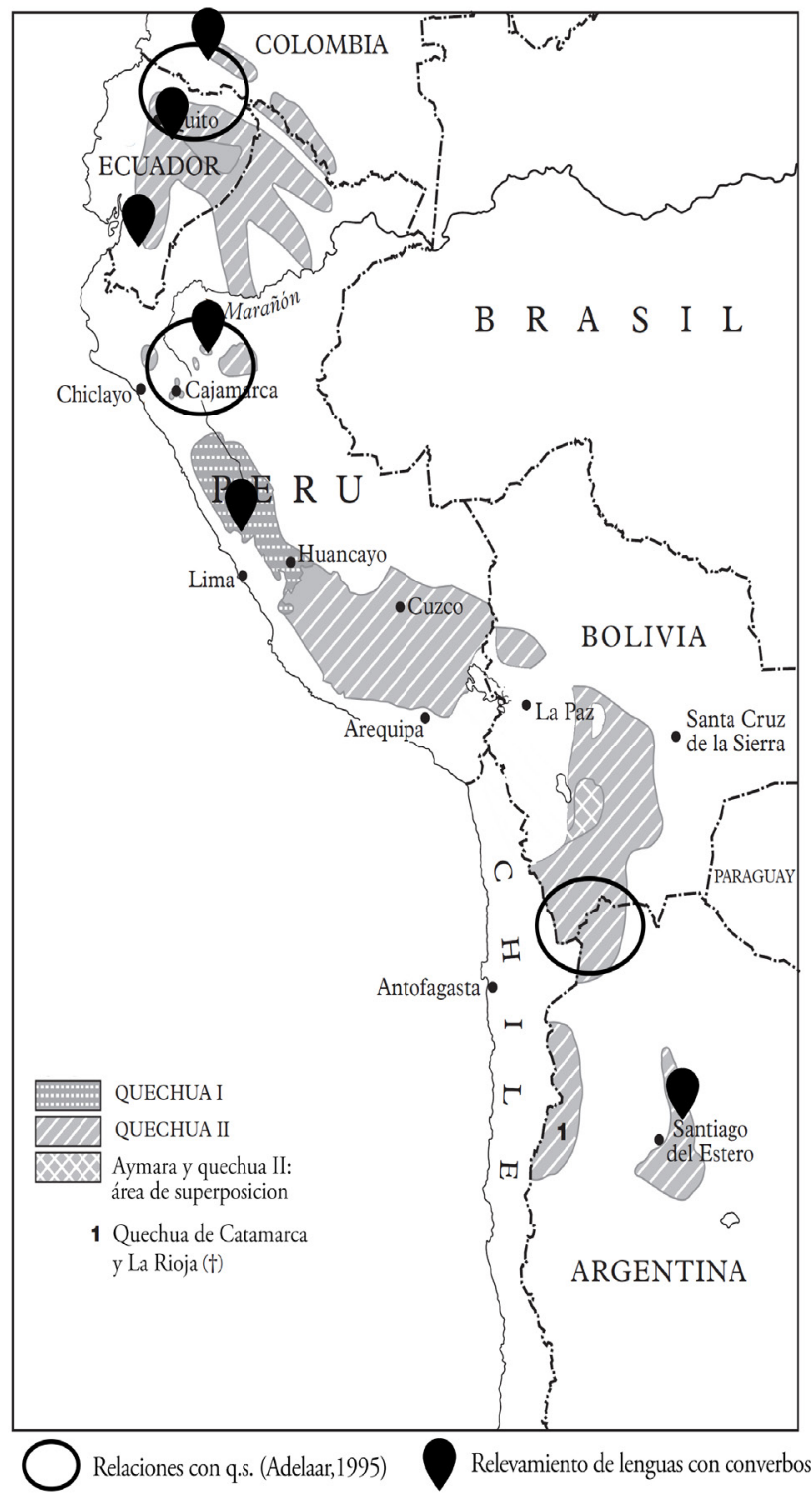




\section{Conclusiones}

Este trabajo se propuso trazar el proceso diacrónico que lleva desde una relación entre dos elementos lingüísticos, es decir, una perífrasis, hacia la formación de nuevos morfemas, con ejemplos del quichua santiagueño. Se notó que una de las construcciones perifrásiticas analizadas, la de aspecto progresivo expresada por un converbo y un verbo cópula auxiliar, actúa como patrón que se encuentra en extensión hacia otras construcciones de la lengua, como son la perífrasis para expresar aspecto habitual y otra para expresar tiempo futuro. Siendo el converbo una forma muy frecuente y multifucional especializada en la expresión de relaciones entre eventos altamente integradas, puede explicarse su predisposición a ser una forma productiva extensible a otras construcciones perifrásticas. Caminos de gramaticalización que se explican como la fusión de dos elementos también han sido encontrados en lenguas quechua norteñas en construcciones similares. Estas misma lenguas son además aquellas que cuentan con una forma similar al converbo del santiagueño para indicar correferencia en las relaciones entre eventos, sin embargo, actualmente su uso y distribución se encuentran, probablemente, subdescritpos. Por lo tanto, se considera aquí que es necesario un estudio comparado de esta forma en las lenguas de la familia para determinar si se trata de construcciones con las mismas funciones y desarrollos diacrónicos similares. Una vez que contemos con más descripciones de estas construcciones en estas y otras lenguas de la familia, será posible apoyar con evidencia sintáctica las observaciones realizadas por otros estudiosos acerca de la relación entre el santiagueño y las lenguas quechua norteñas. Se espera, por tanto, que el presente trabajo abra una puerta hacia nuestra comprensión de la relación entre lenguas de la familia quechua y sus caminos de gramaticalización.

\section{Abreviaturas}

1 primera persona; 2 segunda persona; 3 tercera persona; AC acusativo; APL aplicativo; BEN benefactivo; CIS cislocativo; COMP comparativo; CONT continuativo; CONV converbo; COP cópula; DEM demostrativo; DIR direccional; DUR durativo; EUF eufónico; EXCL exclusivo; FUT futuro; IMP imperativo; LOC locativo; MED medial; MS mismo sujeto; NEG negación; NMLZ nominalizador; OBJ objeto; PAS pasado; PL plural; POS posesivo; PROG progresivo; PROP propietivo; RFL reflexivo; SG singular; V verbo. 


\section{Referencias}

ADELAAR, W. F H. Tarma Quechua: Grammar, Texts, Dictionary. Leiden: Brill. 1977.

ADELAAR, W. F. H. Morfología del quechua de Pacaraos. Lima: Universidad Nacional Mayor de San Marcos; Instituto de Lingüística Aplicada, 1986.

ADELAAR, W. F. H. Raíces lingüísticas del quichua de Santiago del Estero. In: SEGUNDAS JORNADAS LINGUIISTICA ABORIGEN. Actas... Buenos Aires: Universidad de Buenos Aires; Facultad de Filosofía y Letras; Instituto de Lingüística. 1994. p. 25-50.

ADELAAR, W.F. H,; P. MUYSKEN. The Languages of the Andes. Cambridge; New York: Cambridge University Press, 2004. DOI: http:// dx.doi.org/10.1017/CBO9780511486852.

AIKHENVALD, A. Multi-verb constructions: Setting the scene. In: AIKHENVALD, A.; P. MUYSKEN, P. (eds.). Multi-verb constructions: a view from the Americas. Leiden: Brill, 2011. p. 1-26.

ALBARRACÍN, L. I. La Quichua : Gramática, ejercicios y diccionario Quichua-Castellano. v. 2. Buenos Aires: Dunken, 2011.

ALBARRACÍN, L. I. La Quichua. Gramática, ejercicios y selección de textos. v. 3. Buenos Aires: Dunken, 2016.

ALDERETES, J. R. El Quechua del Santiago del Estero, gramática y vocabulario. Tucumán: Universidad Nacional de Tucumán, 2001.

BARĐDAL, J. Productivity. Cal.8. Amsterdam: John Benjamins Publishing Company, 2008.

BARĐDAL, J.; EYTHÓRSSON T. Reconstructing Syntax : Construction Grammar and the Comparative Method. In: BOAS, H. C.; SAG, I. A. (eds.). Sign-Based Construction Grammar. Stanford: CSLI Publications, 2012. p. 257-308.

BARĐDAL, J.; SILDEA, S.; E. SNOVA, E.; L. OMM, L. Diachronic Construction Grammar. Amsterdam: John Benjamins Publishing Company, 2015.

BRAVO, D. A. Estado actual del quichua santiagueño. Tucumán: Universidad Nacional de Tucumán, Facultad de Filosofía y Letras, 1965.

BYBEE, J. L. Morphology: A Study of the Relation Between Meaning and Form. Amsterdam: John Benjamins Publishing, 1985. 
CERRÓN-PALOMINO, R. Lingüística quechua. Cuzco: Centro de Estudios Rurales Andinos Bartolomé de las Casas, 2003.

COLE, P. Switch-Reference in Two Quechua Languages. In: EYTHORSSON, J. (ed.. Typological Studies in Language. Amsterdam: John Benjamins Publishing Company, 1983. p. 1-15. DOI: https://doi. org/10.1075/tsl.2.03col.

CRISTOFARO, S. Subordination. Oxford studies in typology and linguistic theory. Oxford; New York: Oxford University Press, 2005.

CRISTOFARO, S. Purpose Clauses. In: DRYER M. S.; HASPELMATH, M. (eds.). The World Atlas of Language Structures Online. Leipzig: Max Planck Institute for Evolutionary Anthropology, 2013. Disponível em: http://wals.info/chapter/125.

CROFT, W. Radical Construction Grammar: Syntactic Theory in Typological Perspective. Radical Construction Grammar. Oxford: Oxford University Press, 2001.

CROFT, W. Typology and Universals. 2a ed. Cambridge: Cambridge University Press, 2003.

CUSIHUAMAN, A. G. Diccionario Quechua Cuzco Collao. Lima: Ministerio de Educación. 1976.

GIPPERT, J.; NIMMELMANN, N.; ULRIKE MOS. Essentials of language documentation. Trends in linguistics. Studies and monographs 178. Berlín; Nueva York: Mouton de Gruyter, 2006.

GISBORNE, N.; A. PATTEN, A Construction Grammar and Grammaticalization. In. HEINE B.; NARROG, H. The Oxford Handbook of Grammaticalization. Oxford: Oxford Handbooks Online, 2011. p. 93100. DOI: https://doi.org/10.1093/oxfordhb/9780199586783.013.0008.

GRANDA, G. de. Un fenómeno de convergencia lingüística por contacto con el quechua de Santiago de Estero. El desarrollo del futuro verbal perifrástico. Revista de Filología Románica, Madrid, v. 1, n. 14, p. 281 1997. DOI: https://doi.org/10.5209/rev_RFRM.1997.v1.n14.12801.

GUILLÍN, C.; O. LÓPEZ; A.TORREZ, A.; M. PÉREZ.; R. GUILLÍN.; Y E. BARRAZA, . Wawqes Pukllas. Libro juvenil quichua. Buenos Aires: En el aura del sauce, 2012.

HARRIS, A. CAMPBELL, L. Historical Syntax in Cross-Linguistic Perspective. Cambridge: Cambridge University Press, 1995. 
HASPELMATH, M. The converb as a cross-linguistically valid category. In: KÖNIG, E.; HASPELMATH, M. (eds.). Converbs in Cross-Linguistic Perspective. 1-56. Empirical Approaches to Language Typology 13. Berlin: Mouton de Gruyter. 1995. p. 1-56.

HEINE, B.; T. KUTEVA. World Lexicon of Grammaticalization. Cambridge: Cambridge University Press, 2002.

HEINE, B.; REH, M. Grammaticalization and Reanalysis in African Languages. Hamburg: H. Buske. 1984.

HINTZ, D. J. El Aspecto Verbal en Quechua. Serie Lingüística Peruana 58. Lima: Instituto Lingüístico de Verano, 2017.

JUANATEY, M. Movimiento con propósito en quichua santiagueño. Forma y Función, Medellín, v. 33, n. 1, p. 63-85, 2020a. DOI: https:// doi.org/10.15446/fyf.v33n1.84181

JUANATEY, M. Relaciones entre eventos y referencialidad en quichua santiagueño: de la gramática al discurso. 2020b. Tesis doctoral - Facultad de Filosofía y Letras, Universidad de Buenos Aires, $2020 \mathrm{~b}$.

KALT, S. Pointing in Space and Time: Deixis and Directional Movement in Schoolchildren's Quechua. In: MANLEY, M.; TENDAM, A. (eds.). Quechua Expressions of Stance and Deixis. BRILL, 2015. p. 25-74.

KERKE, S.; P. MUYSKEN. Quechua Mu and the Perspective of the Speaker. Unity in Diversity. Berlin: De Gruyter Mouton,. 2011.

LEHMANN, C. Grammaticalization: Synchronic variation and diachronic change. Lingua e Stile, Pavia, v. 20, p. 303-318, 1985.

LEHMANN, C. Towards a typology of clause linkage. In: HAIMAN, J.; THOMPSON, S. A. (eds.). Clause combining in grammar and discourse. Amsterdam \& Philadelphia: J. Benjamins. 1988. p. 181-225.

LEHMANN, W. P. Objectives of a Theory of Syntactic Change. Berlin: De Gruyter Mouton. 1995.

MUNRO, P. Field Linguistics. In: ARONOFF, M.; RESS-MILLER, J. (eds.). The Handbook of Linguistics. Oxford: Blakwell. 2001.p. 130-149.

NARDI, R. L. J. Introducción al quichua santiagueño. ALBRRACÍN, L.; ALDERETES, R.; TÉBES, C. (ed.). Buenos Aires: Dunken, 2002.

NEDJALKOV, V. P. Some topological parameters of converbs. In: KÖNIG, E.; HELMATH, M. (eds.). Converbs in Cross-Linguistic 
Perspective.. Empirical Approaches to Language Typology, 13. Berlin: Mouton de Gruyter. 1995. p. 97-136.

NUCKOLLS, J B. The Grammar and Images of Aspect in Lowland Ecuadorean Quechua. 1990. Tesis (Ph. D.) - Department of Linguistics, University of Chicago, 1990.

PARKER, G. La clasificación genética de los dialectos quechuas. In: CERRÓN-PALOMINO, R (ed.). Trabajos de lingüística histórica quechua. Lima: Fondo Editorial Pontificia Universidad Católica del Perú 2014. p. 33-49.

TAYLOR, G. Diccionario quechua Chachapoyas-Lamas. Lima: IFEA: IEP: Editorial Commentarios, 2006.

TEBES, M. C. Castañumanta yuyayniy. Ni los años ni la distancia. Buenos Aires: Dunken, 2009.

TORERO, A. Idiomas de los Andes: lingüística e historia. Lima: IFEA, Instituto Francés de Estudios Andinos, 2002.

TRAUGOTT, E. Toward a coherent account of grammatical constructionalization. In: BARĐDAL, J.; GILDEA, S.; E. SMIRNOVA, E.; L. SOMMERER, L. (eds.). Diachronic Construction Grammar. Amsterdam: John Benjamins Publishing Company, 2015. p. 51-80. DOI: https://doi.org/10.1075/cal.18.02tra.

VAN VALIN, R. D. Exploring the syntax-semantics interface. Cambridge; New York: Cambridge University Press, 2005.

WEBER, D. A Grammar of Huallaga (Huánuco) Quechua. California: University of California Press, 1989.

ZARIQUIEY, R.; CÓRDOVA, G. Qayna, kunan, paqarin. Una introducción práctica al quechua chanca. Lima: Pontificia Universidad Católica del Perú. Estudios Generales Letras. 2008. 